\title{
Sequential Occurrence of Hepatocellular Carcinoma Following Waldenström's Macroglobulinemia: The Pathogenetic Role of Chronic Liver Disease
}

\author{
Tohru Izumi, Ryuhei Sasaki, Saburo Tsunoda*, Makio Hatakeyama**, \\ Hirotaka Koyama**, Naohiro ShinOHARA*** and Yasusada MiURA
}

\begin{abstract}
We report a case of sequential occurrence of hepatocellular carcinoma (HCC) following Waldenström's macroglobulinemia (WM) in the course of chronic liver disease. The diagnosis of WM was made in a 55-year-old man with a history of alcohol abuse. He developed HCC in the course of $\mathrm{WM}$, and hepatitis $\mathrm{C}$ virus $(\mathrm{HCV})$ infection was detected by enzyme-linked immunosorbent assay. Recent reports suggest that persistent $\mathrm{HCV}$ infection is related to the pathogenesis of $\mathrm{B}$ cell malignancy. Chronic liver disease may be associated with the pathogenesis of the double malignancies in the present case.
\end{abstract}

(Internal Medicine 35: 416-418, 1996)

Key words: $\mathrm{B}$ cell malignancy, hepatitis $\mathrm{C}$ virus, alcohol abuse

\section{Introduction}

Hepatocellular carcinoma (HCC) is frequently associated with other malignancies (1). We present a case of sequential occurrence of HCC following Waldenström's macroglobulinemia (WM) in the course of chronic liver disease, and discuss the pathogenesis of the double malignancies in the present case.

\section{Case Report}

A 55-year-old man was admitted to the hospital because of slight fever in February 1988. He had no previous exposure to blood transfusion. His daily intake of alcohol was about $200 \mathrm{ml}$. Physical examination showed hepatosplenomegaly. Hematological findings were as follows; hemoglobin $9.4 \mathrm{~g} / \mathrm{dl}$,

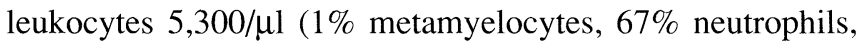
$18 \%$ lymphocytes, $12 \%$ monocytes and $2 \%$ eosinophils), and platelets $30.5 \times 10^{4} / \mu 1$. Other laboratory findings were as follows; aspartate aminotransferase (AST) $52 \mathrm{mU} / \mathrm{ml}$ (normal range, 11-30), alanine aminotransferase (ALT) $67 \mathrm{mU} / \mathrm{ml}$ (normal range, 4-30), alkaline phosphatase (ALP) $485 \mathrm{mU} / \mathrm{ml}$ (normal range, 89-285), total protein $9.9 \mathrm{mg} / \mathrm{dl}[26.6 \%$ albumin, $5.6 \% \alpha_{1}$-globulin, $12.6 \% \alpha_{2}$-globulin, $9.4 \% \beta$-globulin and $45.5 \% \gamma$-globulin with monoclonal protein (IgM-k)], total bilirubin $0.4 \mathrm{mg} / \mathrm{dl}$ (normal range, $0.2-1.0$ ), and IgM 2,890 mg/ dl. Hepatitis B surface antigen (HBsAg) and antibody against HBsAg were negative. Ultrasonography of the abdomen showed mild hepatomegaly without a space-occupying lesion and marked splenomegaly $(135 \times 54 \mathrm{~mm})$. Bone marrow examination revealed normocellularity with an increase of lymphoplasmacytic series (Fig. 1). Cryoglobulin and pyroglobulin were negative. He was diagnosed as having WM. He had two courses of melphalan and prednisolone (MP) in combination with vincristine. After his discharge from hospital in March 1988, forty-four courses of MP were administered until November 1991. No blood transfusion was administered before the second admission. The accumulative dose of melphalan was $1,002 \mathrm{mg}$.

Three months before the second admission a high fever developed. He was admitted again in December 1991. Table 1 shows the laboratory data on the second admission. The antibody against HCV (HCVAb) was detected by the second generation enzyme-linked immunosorbent assay (ELISA) (2). Ultrasonography of the abdomen showed splenomegaly $(147 \times$ $48 \mathrm{~mm}$ ) and a high echoic mass in the 5th and 8th segments of the liver. Aspiration biopsy of the liver revealed hepatocellular carcinoma (Fig. 2). His condition soon changed adversely. He

From Division of Hematology, Department of Medicine, Jichi Medical School, Tochigi, *Division of Hematology, Tochigi Cancer Center, Utsumomiya, **Department of Medicine, Utsunomiya Social Insurance Hospital, Utsunomiya and ***Department of Pathology, Hokushin General Hospital, Nakano Received for publication August 30, 1995; Accepted for publication February 26, 1996

Reprint requests should be addressed to Dr. Tohru Izumi, Division of Hematology, Department of Medicine, Jichi Medical School, 3311-1 Yakushiji, Minamikawachi-machi, Tochigi 329-04 


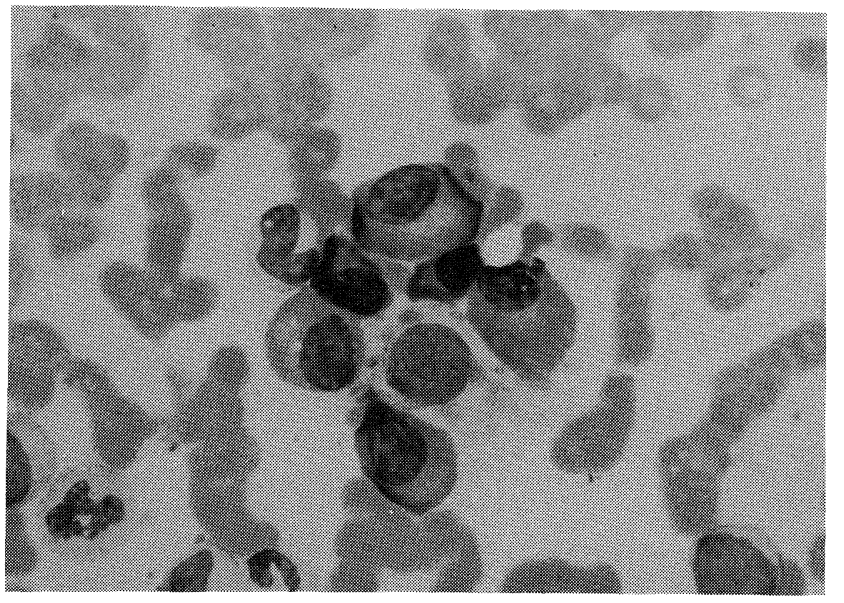

Figure 1. Bone marrow examination demonstrated an increase of lymphoplasmacytic series (Wright-Giemsa stain, $\times 1,000$ ).

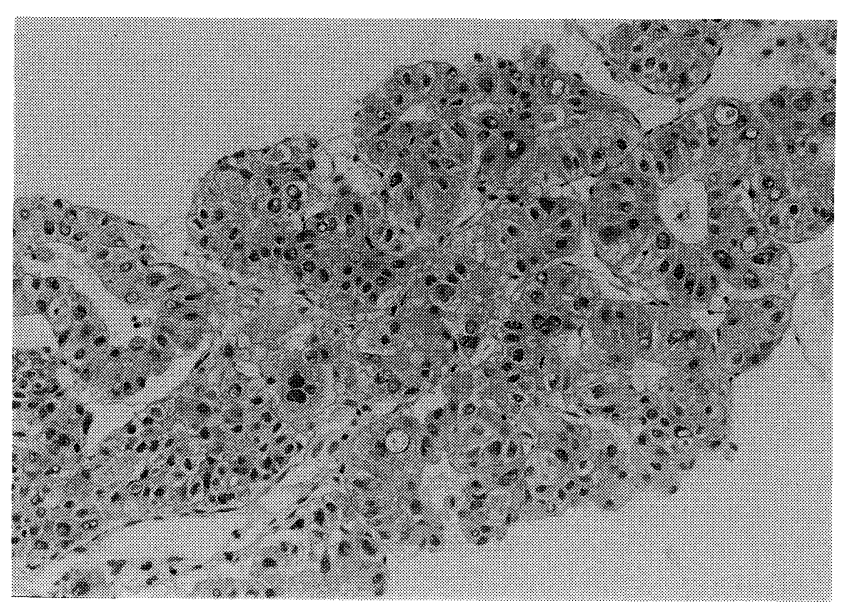

Figure 2. Aspiration biopsy of the liver revealed hepatocellular carcinoma with pseudoglandular pattern (HE stain, $\times 100$ ) died of hepatic failure in March 1992. No autopsy was performed. Figure 3 summarizes the clinical course.

\section{Discussion}

Only a few cases of WM accompanied by $\mathrm{HCC}$ have been reported, most of the patients were Japanese $(3,4)$. WM is a rare B-cell neoplasia, the pathogenesis of which is little known.

Table 1. Laboratory Data on the Second Admission

\begin{tabular}{|c|c|c|c|}
\hline \multicolumn{2}{|l|}{ Peripheral blood } & $\mathrm{IgG}$ & $2,389 \mathrm{mg} / \mathrm{dl}$ \\
\hline Leucocytes & $2,400 / \mu l$ & $\operatorname{IgM}$ & $1,490 \mathrm{mg} / \mathrm{dl}$ \\
\hline Neutrophils & $67.0 \%$ & $\operatorname{Ig} \mathrm{A}$ & $106 \mathrm{mg} / \mathrm{dl}$ \\
\hline Eosinophils & $1.0 \%$ & $\mathrm{C} 3$ & $61 \mathrm{mg} / \mathrm{dl}$ \\
\hline Monocytes & $7.0 \%$ & $\mathrm{C} 4$ & $16 \mathrm{mg} / \mathrm{dl}$ \\
\hline Lymphocytes & $25.0 \%$ & \multicolumn{2}{|c|}{ Antinuclear antibody $\quad 160 x$} \\
\hline Hemoglobin & $11.6 \mathrm{~g} / \mathrm{dl}$ & \multicolumn{2}{|c|}{ Rheumatoid arthritis } \\
\hline Hematocrit & $35.0 \%$ & \multicolumn{2}{|c|}{ hemagglutination } \\
\hline Reticulocytes & $12 \%$ & (RAHA) & $1,280 \times$ \\
\hline Platelets & $84,000 / \mu \mathrm{l}$ & PIVKA-II & $1.6 \mathrm{AU} / \mathrm{ml}$ \\
\hline \multirow[t]{2}{*}{ Prothrombin time } & \multirow[t]{2}{*}{$69 \%$} & \multicolumn{2}{|c|}{ (normal range $<0.1$ ) } \\
\hline & & HBsAg & negative \\
\hline \multicolumn{2}{|l|}{ Biochemistry } & Anti-HBs & negative \\
\hline Total bilirubin & $2.1 \mathrm{mg} / \mathrm{dl}$ & Anti-HCV & positive \\
\hline Direct bilirubin & $1.2 \mathrm{mg} / \mathrm{dl}$ & Cryoglobul & negative \\
\hline AST & $150 \mathrm{mU} / \mathrm{ml}$ & Pyroglobul & negativ \\
\hline $\mathrm{ALT}$ & $138 \mathrm{mU} / \mathrm{ml}$ & & \\
\hline \multicolumn{2}{|c|}{ Lactate dehydrogenase } & \multirow{5}{*}{\multicolumn{2}{|c|}{$\begin{array}{l}\text { Bone marrow (BM) biopsy } \\
\text { Hypocellular bone marrow } \\
\text { with focal plasmatoid cells } \\
\text { and lymphocyte aggregation }\end{array}$}} \\
\hline$(\mathrm{LDH})$ & $519 \mathrm{mU} / \mathrm{ml}$ & & \\
\hline ALP & $188 \mathrm{mU} / \mathrm{ml}$ & & \\
\hline Amylase & $120 \mathrm{mg} / \mathrm{dl}$ & & \\
\hline Cholinesterase & $0.17 \Delta \mathrm{pH}$ & & \\
\hline Urea nitrogen & $8.4 \mathrm{mg} / \mathrm{dl}$ & \multirow{4}{*}{\multicolumn{2}{|c|}{$\begin{array}{r}\text { Chromosomal analysis }(\mathrm{BM}) \\
\text { Normal karyotype }(46, \mathrm{XY})\end{array}$}} \\
\hline Creatinine & $0.5 \mathrm{mg} / \mathrm{dl}$ & & \\
\hline Calcium & $8.6 \mathrm{mg} / \mathrm{dl}$ & & \\
\hline Phosphate & $3.4 \mathrm{mg} / \mathrm{dl}$ & & \\
\hline
\end{tabular}

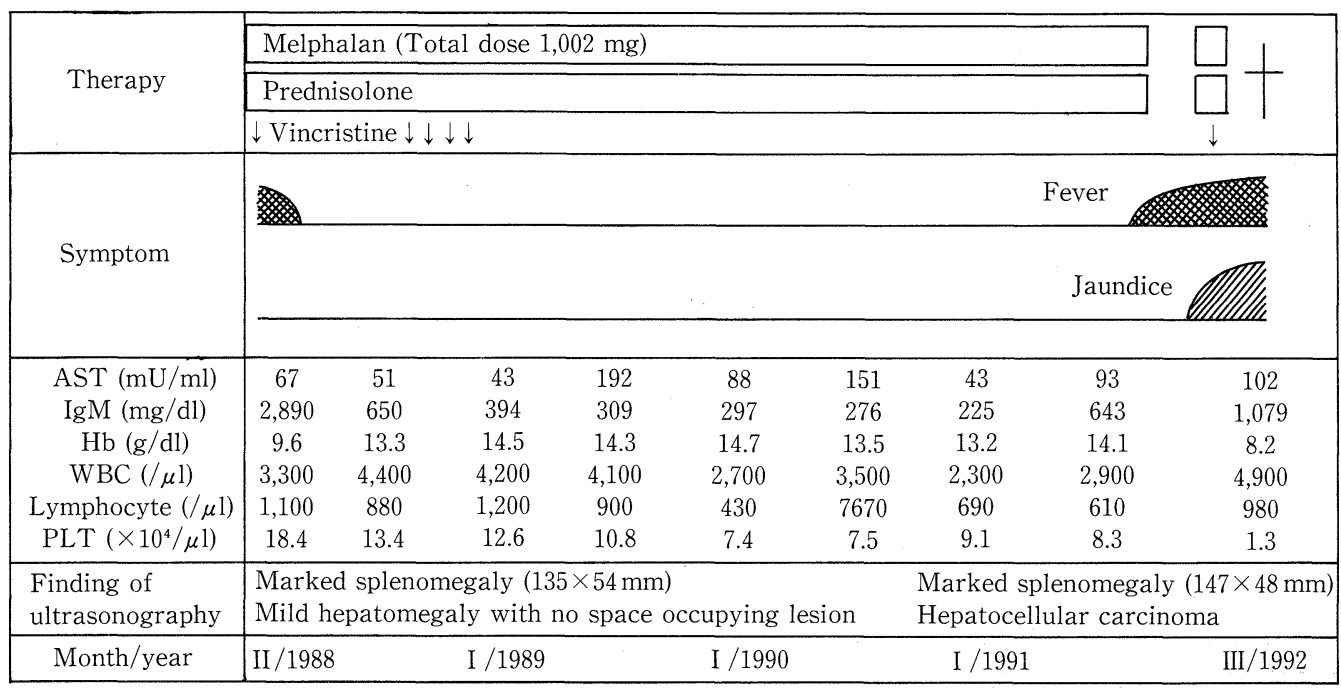

Figure 3. Clinical course. 
Heimann et al (5) reported a high incidence of liver cirrhosis in the patients with chronic lymphoproliferative disorders. The present study suggests the relationship between the occurrence of WM and chronic liver disease. The cause of chronic liver disease was not determined in the present case. The history of alcohol abuse was pointed out, and might have been the primary cause of the liver dysfunction. Alcohol may be related to some types of solid cancer such as HCC (6), and WM (7). In the present case, alcohol might have affected the natural course of WM and HCC. However, other causes of chronic liver disease can not be ruled out, such as hepatitis A and C. Unfortunately, no antibodies against hepatitis A virus were examined. HCVAb was detected in December 1991, although HCVAb was not examined at the onset of WM in this patient. HCV infection might have preceded the onset of WM, because liver dysfunction coexisted with WM in February 1988, and there was no evidence of exposure to $\mathrm{HCV}$ such as a blood transfusion before December 1991.

A high incidence of HCV infection has been reported in patients with lymphoid malignancy, such as WM (8), nonHodgkin's lymphoma (NHL) $(9,10)$ and monoclonal gammopathies with cryoglobulinemic activity (11) in Italy. We also reported a high incidence of $\mathrm{HCV}$ infection in patients affected with B cell malignancies (12). These studies suggest that $\mathrm{HCV}$ infection is involved in the pathogenesis of WM. $\mathrm{HCV}$ replicates in the B lymphocytes in patients with WM (8), nevertheless, the direct relationship between $\mathrm{B}$ cell malignancies and HCV infection is unknown. HCV may induce $p 53$ transitional mutation in HCC, and may be involved in hepatocarcinogenesis (13). Persistent HCV infection might influence the growth of B lymphocytes in the case of WM, which is similar to HCC.

As the previous studies on WM associated with HCC were carried out before the serological assay for HCV became available, the involvement of HCV infection in the pathogenesis of the double malignancies was not discussed $(3,4)$. Recently, Ono et al (14) reported a case of primary splenic lymphoma (B cell type) associated with HCC. Interestingly, HCV infection and history of alcohol abuse were documented in that case.

Chlorambucil and cyclophosphamide are widely used for the treatment of WM (15). However, chlorambucil is not available in Japan, and cyclophosphamide may induce liver dysfunction (16). In contrast, melphalan at usual doses rarely causes hepatotoxicity (16). Therefore, we used melphalan as the alternative to the above drugs in this case. Melphalan is known to induce secondary myelodysplastic syndrome and acute myeloid leukemia (17), however, the association of melphalan with the occurrence of $\mathrm{HCC}$ is not well known.

Several factors including alcohol abuse and $\mathrm{HCV}$ infection may be responsible for the occurrence of WM and HCC in the present case. Further studies are needed to clarify the pathogenesis of WM.

\section{References}

1) Makino H, Morioka K, Takazakura E, Arai K, Takeyama S, Hoso M. Clinical study of hepatocellular carcinoma associated with extrahepatic malignancies. Gan No Rinsyo 41: 858, 1995 (in Japanese, abstract in English).

2) Mimms L, Vallari D, Ducharme L, Holland P, Kuramoto IK, Zeldis J. Specificity of anti-HCV ELISA assessed by reactivity to three immunodominant HCV regions. Lancet 336: 1590, 1990.

3) Shimizu K, Kunii A, Ohnishi K, Hara K, Hirabayashi N, Kodama Y. A case report of pleuropulmonary Waldenström's macroglobulinemia associated with hepatocellular carcinoma. Acta Haematol Jpn 45: 792, 1982.

4) Yamamoto K, Tohda S, Miki T, et al. Acute myeloblastic leukemia and hepatocellular carcinoma following Waldenström macroglobulinemia. Rinsyo Ketsueki (Jpn J Clin Hematol) 31: 984, 1990 (in Japanese, abstract in English).

5) Heimann R, Ray MB, Desmet VJ. HBsAg, chronic lymphoproliferative disorders, and cirrhosis of liver. J Clin Pathol 30: 817, 1977.

6) Blot WJ. Alcohol and cancer. Cancer Res 52 (suppl): 2119, 1992.

7) Tazawa R, Oka Y, Nakamura Y, Takahashi A. Alcoholic liver cirrhosis with macroglobulinemia - a case report. Nippon Syoukakibyou Gakkai Zasshi 87: 2656, 1990 (in Japanese).

8) Santini GF, Crovatto M, Modolo ML, Martelli P, Silvia C, Mazzi G. Waldenström macroglobulinemia: A role of $\mathrm{HCV}$ infection? Blood 82: 2932, 1993.

9) Pozzato G, Mazzaro C, Crovatto M, et al. Low-grade malignant lymphoma, hepatitis $\mathrm{C}$ virus infection, and mixed cryoglobulinemia. Blood 84: 3047, 1994.

10) Ferri $C$, Caracciolo $F$, Zignego AL, et al. Hepatitis $C$ virus infection in patients with non-Hodgkin's lymphoma. Br J Haematol 88: 392, 1994.

11) Mussini C, Ghini M, Mascia MT, et al. Monoclonal gammopathies and hepatitis C virus infection. Blood 85: 1144, 1995.

12) Izumi T, Sasaki R, Miura $Y$, Okamoto $H$. B cell malignancy and hepatitis C virus infection. Leukemia Res, 1996 (in press).

13) Teramoto $T$, Satonaka K, Kitazawa S, Fujimori T, Hayashi K, Maeda S. p53 gene abnormalities are closely related to hepatoviral infections and occur at a late stage of hepatocarcinogenesis. Cancer Res 54: 231, 1994.

14) Ono T, Komatsu M, Masamune O. Primary lymphoma of the spleen with hepatocellular carcinoma. Int Med 34: 261, 1995.

15) Kyle RA. Waldenström's Macroglobulinaemia. in: Myeloma, Biology and Management, Malpas JS, Bergsagel DE, Kyle R, Eds. Oxford Medical Publications, Oxford, 1995, p. 543.

16) Perry MC. Chemotherapeutic agents and hepatotoxicity. Semin Oncol 19: $551,1992$.

17) Cuzick J, Erskine S, Edelman D, Galton DAG. A comparison of the incidence of the myelodysplastic syndrome and acute myeloid leukaemia following melphalan and cyclophosphamide treatment for myelomatosis. Br J Cancer 55: 523, 1987. 